\title{
Working harder to obtain more snack foods when wanting to eat less
}

Citation for published version (APA):

Giesen, J. C. A. H., Havermans, R. C., Nederkoorn, C., Strafaci, S., \& Jansen, A. T. M. (2009). Working harder to obtain more snack foods when wanting to eat less. Behaviour Research and Therapy, 47(1), 1317. https://doi.org/10.1016/j.brat.2008.09.007

Document status and date:

Published: 01/01/2009

DOI:

10.1016/j.brat.2008.09.007

Document Version:

Publisher's PDF, also known as Version of record

\section{Document license:}

Taverne

\section{Please check the document version of this publication:}

- A submitted manuscript is the version of the article upon submission and before peer-review. There can be important differences between the submitted version and the official published version of record.

People interested in the research are advised to contact the author for the final version of the publication, or visit the DOI to the publisher's website.

- The final author version and the galley proof are versions of the publication after peer review.

- The final published version features the final layout of the paper including the volume, issue and page numbers.

Link to publication

\footnotetext{
General rights rights.

- You may freely distribute the URL identifying the publication in the public portal. please follow below link for the End User Agreement:

www.umlib.nl/taverne-license

Take down policy

If you believe that this document breaches copyright please contact us at:

repository@maastrichtuniversity.nl

providing details and we will investigate your claim.
}

Copyright and moral rights for the publications made accessible in the public portal are retained by the authors and/or other copyright owners and it is a condition of accessing publications that users recognise and abide by the legal requirements associated with these

- Users may download and print one copy of any publication from the public portal for the purpose of private study or research.

- You may not further distribute the material or use it for any profit-making activity or commercial gain

If the publication is distributed under the terms of Article $25 \mathrm{fa}$ of the Dutch Copyright Act, indicated by the "Taverne" license above, 


\title{
Working harder to obtain more snack foods when wanting to eat less
}

\author{
Janneke C.A.H. Giesen*, Remco C. Havermans, Chantal Nederkoorn, Silvana Strafaci, Anita Jansen \\ Department of Clinical Psychological Science, Faculty of Psychology, Maastricht University, P.O. Box 616, 6200 MD Maastricht, The Netherlands
}

\section{A R T I C L E I N F O}

\section{Article history:}

Received 3 June 2008

Received in revised form 4 September 2008

Accepted 23 September 2008

\section{Keywords:}

Dieting

Food reinforcement

Obesity

Restraint

\begin{abstract}
A B S T R A C T
This study investigates individual differences in the reinforcing value of snack food. More specifically, it was investigated whether differences in restraint status are associated with differences in working for high-caloric snack food. Thirty-six unrestrained non-dieters, twenty restrained non-dieters and fifteen current dieters performed a concurrent schedules task in which they had the option to work for points for either snack food or fruit and vegetables. By progressively increasing the "price" of the snack foods (i.e., the amount of work required to obtain extra snack points) the relative reinforcing value of snack food was determined. As hypothesized, restrained non-dieters worked harder and current dieters worked less hard to obtain snack food as compared to unrestrained non-dieters.
\end{abstract}

(C) 2008 Elsevier Ltd. All rights reserved.

\section{Introduction}

World wide, the incidence of overweight and obesity is increasing and this is problematic as especially obesity can have grave consequences for one's health. Overweight is the result of a positive energy balance, meaning that more energy is consumed than expended. As a low level of physical activity is less likely to account for excessive weight gain, food intake can be considered as the most important determinant of changes in energy homeostasis (Jéquier, 2002). According to this line of reasoning, obesity is mainly the result of overeating (i.e., excessive caloric intake). Why some people tend to overeat is still unclear, though a specific group of people at risk for developing overweight and obesity have been found to be people with high self-reported dietary restraint. In the short term, dieting leads to weight loss, but somewhat paradoxically, on a longer term dietary restraint actually predicts weight gain (Drapeau, Provencher, Lemieux, \& Despres, 2003; Klesges, Isbell, \& Klesges, 1992; Lowe et al., 2006; Stice, Cameron, Killen, Hayward, \& Taylor, 1999; Stice, Presnell, Shaw, \& Rohde, 2005).

Restrained eaters are concerned about their body weight and shape and, therefore, try to restrict their food intake. However, as dietary restraint appears to predict long term weight gain, it is clear that restrained eaters are not particularly successful at their weight control attempts (Heatherton, Herman, Polivy, King, \& McGree, 1988). Indeed, restrained eaters have been found to overeat after a high-caloric preload. In their seminal study, Herman and Mack

\footnotetext{
* Corresponding author. Tel.: +31 43 3881460; fax: +31 433884196. E-mail address: janneke.giesen@psychology.unimaas.nl (J.C.A.H. Giesen).
}

(1975) presented their participants with no, one or two milkshakes as a preload. After consuming the preloads, participants had to taste three different flavors of ice-cream. The amount of ice-cream consumed was measured. Participants scoring low on restraint consumed less ice-cream as the preload increased, whereas the high restrained participants consumed more ice-cream following the preload than without the preload. Whether the preload consisted of one or two milkshakes did not make a difference in the amount of ice-cream consumed by the high restrained participants. The finding of overeating after a preload has been called counterregulation. One explanation for this counter-regulation is that restrained eaters consider their diet to be broken after the consumption of a high-caloric preload and this triggers disinhibited eating in the restrained eater (Herman \& Mack, 1975; Polivy, 1976). Such disinhibitive cognitions are, however, not a prerequisite for triggering disinhibited eating. Jansen and Van den Hout (1991), for example, demonstrated counter-regulation in restrained eaters after merely smelling a preload. In this case, the thought of breaking a diet could not have been the reason for overeating since the participants did not consume the preload. Further, a study by Urbszat, Herman, and Polivy (2002) showed that restrained eaters also demonstrate disinhibited eating when anticipating to go on a diet the next day. Negative affect and anxiety have also been found to trigger overeating in restrained eaters. Restrained eaters who were shown a frightening film ate more food during a taste test than restrained eaters who saw an emotionally neutral film did. Unrestrained eaters' eating behavior was unaffected by the manipulation (Schotte, Cools, \& McNally, 1990; see also, Polivy, Herman, \& McFarlane, 1994). Restrained eaters thus seem to be triggered to overeat in various situations and by different cues. 
However, there are a few studies that failed to demonstrate consistent disinhibition in restrained eaters. This equivocal finding can be attributed to the fact that, typically, restrained eaters express body, weight, and shape concerns and the desire to lose weight but are not necessarily dieting (Lowe, 1993). Indeed, the restrained eaters that do diet (the so called current dieters; CDs), do not show disinhibition; that is, in a laboratory setting they do not show counter-regulation after the consumption of a preload (Lowe, 1995; Lowe, Whitlow, \& Bellwoar, 1991). According to the three-factor model of dieting (Lowe, 1993), CDs can successfully regulate their caloric intake at least temporarily and, therefore, one should distinguish CDs from restrained non-dieters (RNDs).

A potential reason for RNDs' tendency to disinhibit may simply be that particularly high-caloric foods are relatively more reinforcing for them than they are for unrestrained eaters (unrestrained non-dieters; UNDs). These foods have a stronger motivational appeal for RNDs than they have for UNDs. However, note that the reinforcing value of food is always a relative value and not an absolute value. When given the choice between performing a task to obtain a high-calorie or low-calorie snack, one may choose to work for the high-calorie snack indicating that the high-calorie snack is more reinforcing than the lowcalorie snack. But when the choice is between a high-calorie snack and a certain amount of money, the same person might choose money over the snack. Because the reinforcing value of food is relative, preference for a low-calorie snack can be interpreted as reflecting approach towards the low-calorie snack, but also as avoidance of the high-calorie snack. This may also explain why CDs do not always demonstrate disinhibited eating as the consumption of high-calorie foods directly interferes with their diet (and the express wish to lose weight). According to this line of reasoning, the momentary relative reinforcing value of high-calorie food should be stronger for RNDs but weaker for CDs as compared with UNDs.

In this experiment it was investigated whether the relative reinforcing value of snack food differs between RNDs, CDs and UNDs as outlined above. This relative reinforcing value of snack food is assessed by means of a concurrent schedules task that measures how hard a participant works for snack food, compared to an alternative, in this case low-caloric food (e.g., Goldfield \& Epstein, 2002). A participant is offered the choice between working for points for snacks and points for low-caloric food. In the beginning the response requirement for earning points for both foods are equal. However, as the task continues the response requirement for earning snack points increases, whereas the response requirement for the low-caloric food points remains the same. The more effort a person makes in earning snack points the higher the relative reinforcing value of snack food. Individual differences in the relative reinforcing value of food have already been observed using a similar task. Saelens and Epstein (1996) found that obese women are more inclined to work for palatable foods as compared to nonobese women. From these results, they concluded that food is more reinforcing for obese women than for non-obese women.

To recapitulate, we hypothesized that RNDs invest more effort in obtaining snack food than UNDs. Additionally we hypothesized that CDs will not show as much effort in working for snack food compared to RNDs and UNDs.

\section{Method}

\section{Participants}

Participants were female introductory psychology and health science students from Maastricht University in the Netherlands. Students were selected based on their scores on three items of the Restraint Scale (RS; Herman \& Polivy, 1980), concerning diet frequency, the influence of a weight fluctuation on their way of life, and feelings of guilt after eating. A pilot study among female undergraduate students $(n=767)$ concerning the validation of selecting participants based on their scores on these three items of the RS revealed that the score on the three items highly correlates with the total score on the complete RS, $r=0.84, p<0.01$. Scores on the complete Restraint Scale range from 0 to 35 . The maximum score to be obtained from these three items chosen from the Restraint Scale is 10. A participant scoring 3 or below on these three items classified as an unrestrained eater, whereas a participant scoring 5 or above was classified as a restrained eater. These cutoffs were chosen as the pilot data indicated that a score of 3 or below on these three items corresponded with a total mean RS score of 7.5, and that the three-item score of 5 and above corresponded with a total mean RS score of 16.4.

At the end of the actual test session, participants were asked whether they were currently dieting to lose weight, which could simply be answered with a "yes" or "no" (see also Lowe \& Timko, $2004)$. On the basis of these data, three groups were formed: the UNDs $(n=36)$, the RNDs $(n=20)$ and the CDs $(n=15)$. All 15 CDs initially classified as restrained eater. Data from four extra participants were excluded from the analysis. Three of them did not grade at least one of the snack foods or fruits and vegetables as sufficiently palatable. One participant misinterpreted the instructions for the experiment. Participant characteristics of the three groups are shown in Table 1. Participants were given one course credit or $\mathrm{a} € 7.50$ monetary voucher for participating in the study. This study was approved by the ethical committee of the Faculty of Psychology.

\section{Procedure and materials}

When invited for the experiment, participants were asked to eat something $2 \mathrm{~h}$ before the experiment and from that time on not to eat until their participation. Participants were told that the experiment was about choice behavior and mental fatigue. All participants were tested individually between noon and $6 \mathrm{PM}$. Once in the lab, participants were presented with bite-size portions of eight different food items. Taking into account that people have different taste preferences, participants were provided with four items from the category 'fruit and vegetables' (cucumber $[ \pm 4 \mathrm{~g}]$, tangerines [ $\pm 5 \mathrm{~g}$ ], white grapes [ $\pm 6 \mathrm{~g}$ ], and canned pineapple chunks $[ \pm 6 \mathrm{~g}]$ [Del Monte Foods, San Francisco]) and four items from the category 'snack food' (chocolate M\&M's [ $\pm 3 \mathrm{~g}$ ] [Masterfoods, Veghel], chocolate chip cookies [ $\pm 3 \mathrm{~g}$ ] [Van Welzen, Smilde Bakery, Edam], sweet pepper flavored chips [ $\pm 2 \mathrm{~g}$ ] [Lay's, Smiths Food Group, Utrecht] and cocktail snacks [ $\pm 2 \mathrm{~g}$ ] [Duyvis Productions, Zaandam]). These eight bite-size portions together contained approximately $55 \mathrm{kcal}$. The eight foods were presented in random order for a paper-and-pencil rating task. Participants were asked to taste

Table 1

Means with standard errors and F-test of group characteristics. ${ }^{a}$

\begin{tabular}{|c|c|c|c|c|c|c|c|}
\hline \multirow[t]{2}{*}{ Variable } & \multicolumn{2}{|c|}{$\begin{array}{l}\text { UNDs } \\
(N=36)\end{array}$} & \multicolumn{2}{|c|}{$\begin{array}{l}\text { RNDs } \\
(N=20)\end{array}$} & \multicolumn{2}{|c|}{$\begin{array}{l}\text { CDs } \\
(N=15)\end{array}$} & \multirow[t]{2}{*}{$F(2,68)$} \\
\hline & $M$ & SE & $M$ & SE & $M$ & SE & \\
\hline Age (years) & $18.9_{\mathrm{a}}$ & 0.2 & $19.1_{a}$ & 0.4 & $19.1_{a}$ & 0.4 & 0.23 \\
\hline 3 items RS & $1.4 \mathrm{a}$ & 0.2 & $6.3_{b}$ & 0.3 & $6.3_{\mathrm{b}}$ & 0.4 & 144.37 \\
\hline BMI (Body Mass Index; kg/m²) & $20.3_{a}$ & 0.4 & $23.1_{b}$ & 0.6 & $25.5_{c}$ & 1.0 & 18.10 \\
\hline Hunger (100 mm VAS) & $54.9_{\mathrm{a}}$ & 3.5 & $51.6_{a}$ & 4.2 & $49.1_{a}$ & 5.1 & 0.48 \\
\hline $\begin{array}{l}\text { Hedonics for most liked } \\
\text { snack food }(0-10)\end{array}$ & $8.5 \mathrm{a}$ & 0.2 & $8.5 \mathrm{a}$ & 0.3 & $8.4_{a}$ & 0.3 & 0.04 \\
\hline $\begin{array}{l}\text { Hedonics for most liked } \\
\text { fruit or vegetable }(0-10)\end{array}$ & $8.6_{a}$ & 0.2 & $8.6 \mathrm{a}$ & 0.2 & $8.9 \mathrm{a}$ & 0.4 & 0.42 \\
\hline
\end{tabular}

\footnotetext{
${ }^{a}$ Means with different subscripts are significantly different from each other, $p<0.05$ (one-tailed).
} 
(and consume) the foods and subsequently rate its momentary palatability (11-points scale: 0 "not at all palatable at the moment" to 10 "highly palatable at the moment"). This rating task was followed by a ranking task, where the participant was asked to rank the eight food items from most palatable at this moment to least palatable at this moment. Because level of hunger may possibly influence the reinforcing value of food (Lappalainen \& Epstein, 1990), participants were asked to indicate how hungry they were at that moment on a $100 \mathrm{~mm}$ Visual Analog Scale (VAS; 0 "not at all hungry" to 100 "very hungry") to be able to check whether the groups did not differ on initial hunger. Next, the participants were presented with a filler-questionnaire concerning choice behavior. This allowed the experimenter time to enter the highest rated snack and the highest rated fruit or vegetable as choice options for the concurrent schedules task into the computer program. Subsequently, participants completed the concurrent schedules task.

Participants were told that they were going to play a computer game in which they had to earn points for food and that the computer would randomly select two of the eight food items they had just evaluated as their choice options. In fact, they were always offered their highest rated snack and their highest rated fruit or vegetable as choice options in the task. Participants were informed that as the game proceeded it would get harder, however, not impossible to earn points for one of the two options. Participants were explained that every ten points equals ten grams of the matching food and that they would have to eat the food that was earned after the game. This instruction served to limit the probability of socially desirable responding by the participant during the task. Points for the different food items could be earned by means of pushing the related key; that is, a left response key corresponding with the high-caloric snack, or a right response key corresponding with the low-caloric alternative (for half of the participants this response key assignment was reversed).

The game consisted of five trials. In every trial, 20 points in total (snack points + fruit/vegetable points) had to be earned. Each trial comprised making a series of choices. For each choice, a picture of the high-calorie snack and fruit/vegetable alternative was presented on screen and the participant was instructed to press the key corresponding to either one of the food options. Immediately after the key press, participants would receive feedback indicating whether they had earned a point for the food item, or not. In the first trial the reinforcement schedules for snacks and fruit or vegetables were both at FR2 (fixed ratio of 2), meaning that after every two responses on the same key a point was earned for the corresponding food. This FR2 reinforcement schedule remained the same for the fruit and vegetable option throughout the task. However, the reinforcement schedule for the high-caloric snack option changed with every trial, from FR2 in the first trial to FR4, FR8, FR16 and FR32 in the fifth and last trial. This means that in the last trial a participant would have to push 32 times on one and the same response key to earn one point for snacks and that if the participant decided to work entirely for snack points in the last trial, she would have to push 640 times on the same response key.

After performing the computer game, when having earned a total of 100 food points (snack + fruit/vegetable points), participants exchanged the points they had earned for the foods and ate it accordingly. Note that each participant thus had to consume a total of $100 \mathrm{~g}$ of food. When having finished eating the foods, participants received a second task: a reaction time (RT) task. In this task, participants simply had to press a response key as fast as possible whenever the letter $X$ appeared on screen. This task had a 5 min duration and served as a filler task in line with the cover story that this study measures the potential effect of making choices on mental fatigue.

After the RT task, participants were asked whether they were currently dieting to lose weight and at the end of the test session, height and weight were measured to calculate Body Mass Index (BMI; $\mathrm{kg} / \mathrm{m}^{2}$ ).

\section{Design and analysis}

The dependent variable is the number of responses for snack food in each trial on the concurrent schedules task. Because the number of points to earn per trial was fixed (i.e., 20 points), the number of responses for fruit and vegetables are not of interest here as they are directly related to the number of responses for snacks. Number of responses for snack food were analyzed in a 5 (trial: FR2, FR4, FR8, FR16, FR32) $\times 3$ (group: UNDs, RNDs, and CDs) mixed repeated measures analysis of variance (ANOVA), with trial as within-subjects factor and group as between-subjects factor. Since we were interested in differences in responses between groups, three subsequent mixed repeated measures analyses were planned with each time two levels of the between-subject factor 'group': RNDs versus UNDs, RNDs versus CDs, and UNDs versus CDs. To control for the violation of the assumption of sphericity, HuynhFeldt epsilon corrections were applied and the corresponding adjusted degrees of freedom are reported for all repeated measures analyses. Partial eta squared $\left(\eta_{\mathrm{p}}^{2}\right)$ is reported as a measure of effect size.

\section{Results}

To test whether the three groups differed from each other on working for snacks across trials, an overall analysis on responses for snack food was performed with all three groups: UNDs, RNDs and CDs. A significant main effect of trial was observed, $F(2.06$, $140.18)=10.91, p<0.001, \eta_{\mathrm{p}}^{2}=0.14$. Also a significant main effect of group was found, $F(2,68)=5.04, p<0.01, \eta_{\mathrm{p}}^{2}=0.13$. These main effects were qualified by a significant trial $\times$ group interaction, $F(4.12,140.18)=3.05, \quad p=0.02, \quad \eta_{\mathrm{p}}^{2}=0.08$. Mean number of responses per trial for each separate group is displayed in Fig. 1. The interaction suggests, in line with our hypotheses, that RNDs work harder to obtain snack food than UNDs, but only when these RNDs are not currently dieting.

To further examine the trial $\times$ group interaction, three separate analyses were conducted with only two levels for the factor group, to be able to compare each group with each other. The first of the

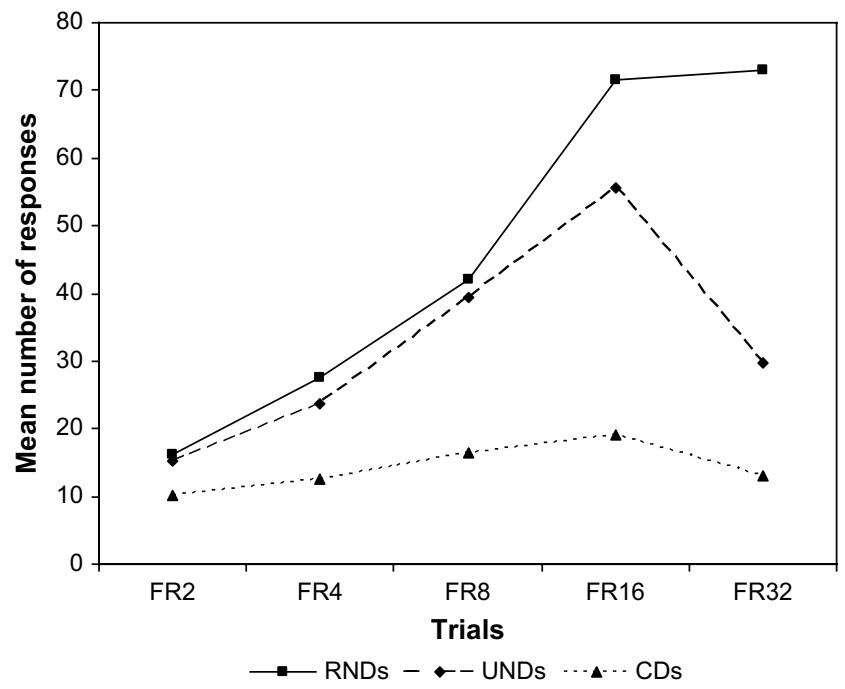

Fig. 1. Mean responses for snack food at different trials for each separate group. Each trial denotes a different response requirement. FR refers to fixed ratio of reinforcement and the numbers refer to the number of responses required to obtain a single snack point. 
three analyses compared UNDs with RNDs on the five trials. Again a significant main effect for trial was found, $F(2.04,110.29)=14.14$, $p<0.001, \eta_{\mathrm{p}}^{2}=0.21$. However, no significant main effect for group was found, $F(1,54)=2.23, p=0.14, \eta_{\mathrm{p}}^{2}=0.04$. The main effect for trial again was qualified by a significant interaction effect, $F(2.04$, $110.29)=3.02, p=0.05, \eta_{\mathrm{p}}^{2}=0.05$. This analysis revealed that as the reinforcement ratio for snacks increases, the RNDs start working harder for snack food compared to the UNDs. As can be inferred from Fig. 1, the number of responses for snack foods only start to diverge between these two groups with a response requirement of 16 responses per snack point (i.e., trial FR16) and this difference is significant at a response requirement of 32 responses per snack point, $t(54)=2.13, p=0.04$.

In a second analysis comparing the UNDs with the CDs, a significant main effect for trial was found, $F(2.41,117.89)=8.56, p<0.001$, $\eta_{\mathrm{p}}^{2}=0.15$. Also a significant group effect was found, $F(1,49)=9.47$, $p<0.01, \eta_{\mathrm{p}}^{2}=0.16$. These trial and group effects were qualified by a significant interaction effect, meaning that UNDs work harder for snacks as reinforcement ratio increases compared to the CDs, $F(2.41$, $117.89)=3.49, p=0.03, \eta_{\mathrm{p}}^{2}=0.07$. Post-hoc tests show that responses given for snacks differ significantly at every trial comparing UNDs with CDs, $t^{\prime} \mathrm{s}>2.04$, $p$ 's $<0.05$. When finally comparing the RNDs with the CDs, a significant trial effect was observed, $F(1.59$, $52.47)=4.15, p=0.03, \eta_{\mathrm{p}}^{2}=0.11$, and group effect was also found significant $F(1,33)=6.70, p=0.01, \eta_{\mathrm{p}}^{2}=0.17$. The trial $\times$ group interaction was marginally significant, $F(1.59,52.47)=2.90, p=0.08, \eta_{\mathrm{p}}^{2}$ $=0.08$. RNDs exert more effort in obtaining high-caloric snack food than the CDs. Again post-hoc tests show that except for trial FR32, the number of responses given for snacks significantly differ at each trial, $t$ 's $>2.44, p$ 's $\leq 0.2$, for trial FR32 this difference was marginally significant, $t(33)=1.96, p=0.06$.

\section{Discussion}

The present study investigated the relative reinforcing value of snack food for UNDs, RNDs and CDs. In line with our hypotheses, we found that RNDs are willing to work much harder to obtain highcaloric snack food when compared to UNDs. Further, CDs do not work as hard for obtaining high-caloric snacks as compared to RNDs and to UNDs. This latter finding is in line with the three-factor model of dieting (Lowe, 1993), which states that CDs do restrict their caloric intake as opposed to RNDs. Lowe et al. (1991) found that CDs especially restrict their caloric intake after a preload. It is possible that the findings in the present experiment are similar because the food rating and tasting prior to the concurrent schedules task functioned as a preload as well (although this preload was considerably smaller than usual). CDs thus work less for snack foods than RNDs. A possible explanation for this is that the explicit goal of losing weight is more salient and desirable for the current dieter, and behavior in line with this current goal (i.e., opting for low-caloric foods, and by doing so effectively avoiding the threatening snack food) is thus relatively more reinforcing than obtaining snack food. Corroborating this line of reasoning, Fishbach and Dhar (2005) demonstrated that female undergraduate students wanting to lose weight chose to have an apple or a chocolate bar after participation in a survey study depending on the degree to which they considered themselves removed from their ideal weight. The closer one perceived to be toward one's ideal weight, the more likely one was to opt for chocolate. Fishbach and Dhar thus state that progress along the goal of weight-loss liberates one to pursue inconsistent goals, such as indulging in high-caloric snack food. Indeed, in the present study, the CDs had a higher BMI than the RNDs, and thus it is conceivable that the CDs perceive less progress in their weight-loss goal than the RNDs. However, we did not directly measure perceived progress in weight-loss, and thus this potential explanation at this point is somewhat speculative and requires further empirical validation. Another possibility is that the fruits and vegetables served as a "diet cue" that prompted the CDs to adhere to their intentions to restrict.

As stated above, the present pattern of results are in line with the three-factor model of dieting proposed by Lowe (1993). According to this model it is hypothesized that CDs are RNDs that currently consider themselves being too heavy and start dieting, and stop their rigorous dieting once they have attained a certain amount of weight-loss, after which they typically regain weight and enter into a cycle of on-and-off dieting. Recently though, Lowe and Timko (2004) proposed an alteration of the three-factor model of dieting, inasmuch that current dieting would not just be a state of restrained eating, but rather refers to a separate group of people who have a longer weight-cycling history by going on-and-off dieting. The present study, however, does not provide any insight into whether CDs are indeed a specific and separate group as we did not assess weight-cycling history of the participants.

In sum, the present pattern of results shows that RNDs work harder for specifically high-caloric foods than UNDs. Evidently, the relative reinforcing value of snack food is larger for RNDs than for UNDs, provided that the restrained eater is not currently dieting to lose weight. This individual difference may underlie the observed difference between RNDs and UNDs in their tendency to overeat, which has been found in past preload studies, and explains why RNDs are generally heavier than UNDs. Initial weight gain may lead to body weight and shape concerns and as such forms an impetus for dieting and a weight-cycling history. In this respect, a high relative reinforcing value of high-caloric food may be an important risk factor for obesity (see also Saelens \& Epstein, 1996). More research, particularly behavioral economic analysis of individual differences in food choice such as the present study, may prove to be beneficial for the development of more efficacious weight-loss programs (Jeffery et al., 2000). Note that the present pattern of results concerns behavior within a laboratory setting. It would be interesting to examine whether a similar pattern can also be observed outside the laboratory. It must be noted that the current study used a sample of university students with a restricted age range, which limits the generalizability of the findings. Moreover, this study used relatively small cell sizes, especially in the CDs group. Future investigations should try to replicate these findings with a larger and more representative sample. Despite these limitations, the current findings may be relevant for understanding different dieting patterns and overeating.

\section{Acknowledgement}

The authors would like to thank Anne Roefs for the helpful discussions on the topic.

\section{References}

Drapeau, V., Provencher, V., Lemieux, S., \& Despres, J. (2003). Do 6-y changes in eating behaviors predict changes in body weight? Results from the Quebec family study. International Journal of Obesity, 27, 808-814.

Fishbach, A., \& Dhar, R. (2005). Goals as excuses or guides: the liberating effect of perceived goal progress on choice. Journal of Consumer Research, 32, 370-377.

Goldfield, G. S., \& Epstein, L. H. (2002). Can fruits and vegetables and activities substitute for snack foods? Health Psychology, 21, 299-303.

Heatherton, T. F., Herman, C. P., Polivy, J., King, G. A., \& McGree, S. T. (1988). The (mis)measurement of restraint: an analysis of conceptual and psychometric issues. Journal of Abnormal Psychology, 97, 19-28.

Herman, C. P., \& Mack, D. (1975). Restrained and unrestrained eating. Journal of Personality, 43, 647-660.

Herman, C. P., \& Polivy, J. (1980). Restrained eating. In A. J. Stunkard (Ed.), Obesity (pp. 208-225). Philadelphia: Saunders.

Jansen, A., \& Van den Hout, M. (1991). On being led into temptation: "counterregulation" of dieters after smelling a "preload". Addictive Behaviors, 16, 247-253.

Jeffery, R. W., Drewnowski, A., Epstein, L. H., Stunkard, A. J., Wilson, G. T., Wing, R. R. et al. (2000). Long-term maintenance of weight loss: current status. Health Psychology, 19(Suppl.), 5-16. 
Jéquier, E. (2002). Pathways to obesity. International Journal of Obesity, 26(Suppl.), $12-17$.

Klesges, R. C., Isbell, T. R., \& Klesges, L. M. (1992). Relationship between dietary restraint, energy intake, physical activity, and body weight: a prospective analysis. Journal of Abnormal Psychology, 101, 668-674.

Lappalainen, R., \& Epstein, L. H. (1990). A behavioral economics analysis of food choice in humans. Appetite, 14(2), 81-93.

Lowe, M. R. (1993). The effects of dieting on eating behavior: a three-factor model Psychological Bulletin, 114, 100-121.

Lowe, M. R. (1995). Restrained eating and dieting: replication of their divergent effects on eating regulation. Appetite, 25, 115-118.

Lowe, M. R., Annunziato, R. A., Markowitz, J. T., Didie, E., Bellace, D. L., Riddell, L. et al. (2006). Multiple types of dieting prospectively predict weight gain during the freshman year of college. Appetite, 47, 83-90.

Lowe, M. R., \& Timko, C. A. (2004). What a difference a diet makes: towards an understanding of differences between restrained dieters and restrained nondieters. Eating Behaviors, 5, 199-208.

Lowe, M. R., Whitlow, J. W., \& Bellwoar, V. (1991). Eating regulation: the role of restraint, dieting, and weight. International Journal of Eating Disorders, 10 461-471.
Polivy, J. (1976). Perception of calories and regulation of intake in restrained and unrestrained subjects. Addictive Behaviors, 1, 237-243.

Polivy, J., Herman, C. P., \& McFarlane. (1994). Effects of anxiety on eating: does palatability moderate distress-induced overeating in dieters? Journal of Abnormal Psychology, 103, 505-510.

Saelens, B. E., \& Epstein, L. H. (1996). Reinforcing value of food in obese and nonobese women. Appetite, 27, 41-50.

Schotte, D. E., Cools, J., \& McNally, R. J. (1990). Film-induced negative affect triggers overeating in restrained eaters. Journal of Abnormal Psychology, 99, 317-320.

Stice, E., Cameron, R. P., Killen, J. D., Hayward, C., \& Taylor, C. B. (1999). Naturalistic weight-reduction efforts prospectively predict growth in relative weight and onset of obesity among female adolescents. Journal of Consulting and Clinical Psychology, 67, 967-974.

Stice, E., Presnell, K., Shaw, H., \& Rohde, P. (2005). Psychological and behavioral risk factors for obesity onset in adolescent girls: a prospective study. Journal of Consulting and Clinical Psychology, 73, 195-202.

Urbszat, D., Herman, C. P., \& Polivy, J. (2002). Eat, drink, and be merry, for tomorrow we diet: effects of anticipated deprivation on food intake in restrained and unrestrained eaters. Journal of Abnormal Psychology, 111, 396-401. 